\title{
Student's perceptions of ethics and academic integrity
}

\author{
Mihaela Suditu ${ }^{\text {a* }}$, Cristina Georgiana Safta ${ }^{\mathrm{a}}$ \\ aPetroleum-Gas University of Ploiești, Bvd. București, no. 39, 100680, Romania
}

\begin{abstract}
This study aims to increase the degree of accountability of educational actors with respect to ethics and academic integrity, by determining the degree of knowledge and compliance with the rules governing ethical and academic conduct, identifying risk factors leading to violation of ethical rules and providing remedial control mechanisms. In this regard, we present a case study carried out with students of the five faculties of the Petroleum and Gas University of Ploiesti. The data are obtained via a questionnaire, analysed and presented tabularly and graphically and the results are explained analytically.
\end{abstract}

Keywords: ethics; academic integrity; academic conduct; accountability

\section{Introduction}

"Ethics of relationships is one of the main areas of every professional ethics" (Gluchman, V., Gluchmanová, M., 2016, p. 1). The university presents itself as an organization whose interests are not limited to the provision of services in accordance with the needs of its beneficiaries, but which also aims to cultivate and assimilate a set of values as grounds for the formation of responsible ethical conduct. In this context, ethical issues are and are becoming issues of major interest being highly relevant to the achievement of its main mission.

The university's attempt to gain the trust of potential students, but also of society as a whole, often faces a major obstacle: the elimination of suspicions regarding compliance with academic ethics and integrity.

In terms of compliance with academic ethics and integrity, it must be said that with the development of technology and the creation of a plagiarism market on the internet, we are witnessing an unprecedented increase in fraudulent behaviour. Globalisation, unlimited access to databases, competitive access to research resources, the complexity of teamwork and the authorship issues it raises, etc., add an ethical dimension of a magnitude that is difficult for a high school graduate or even a student to anticipate; it is the argument that requires increased awareness of the dangers of breaching academic ethics and integrity both by students and especially by professors working in higher education. Our observations entitle us to state that very often, we learn from discussions with students that a number of concepts in the field of ethics are true forms without substance, they are just words, clichés, used only because situations, contexts often require it, merely to create a politically correct image but which they actually use without a scientific and thorough knowledge of their meaning, without a well-grounded culture to back them up.

* Mihaela Suditu. Tel.: +4-0722-287-878;

E-mail address: msuditu@upg-ploiesti.ro 
"Academic integrity has been defined as involving «understanding what it means to be honest in the particular culture of the academic world, and being able to apply the scholarly conventions of acknowledgment» (East and Donnelly 2012). Turner and Beemsterboer (2003) include the notions of teaching, learning and the wider academic environment, and define academic integrity as «honesty in all matters relating to endeavours of the academic environment», which includes «the teaching and learning of knowledge, skills, and values and the discovery and dissemination of new knowledge», Within the past decade, there has been a change in focus on academic integrity from detection and punishment of undesired behaviours to promotion of desired behaviours". (Löfström, E., Trotman, T., Furnari, M., 2015, p. 435).

Therefore, we consider it appropriate to present the fundamental working concepts and analyse their implications at the academic level. We begin our approach by describing moral values grouped into four categories (see Université du Québec à Chicoutimi) (pp. 4-15):

- social values;

- community values;

- professional values;

- individual values.

Each category contains a number of corresponding values, as shown in the table below:

Table 1. Categories of moral values

\begin{tabular}{cccc}
\hline SOCIAL & COMMUNITY & PROFESSIONAL & INDIVIDUAL \\
VALUES & VALUES & VALUES & VALUES \\
\hline Education & Loyalty & Competence & Equality \\
Culture & Solidarity & Assiduity, & Dignity \\
Pluralism & Dialogue & Perseverance & Respect \\
Multiculturalism & Involvement & Scientific integrity, & Discretion \\
Work & Advocacy & Intellectual Property & Fraternity \\
Technological & Interdisciplinarity & Probity & Justice \\
development & Collaboration & Transparency & Fairness \\
Well-being & & Continuity & Impartiality \\
Environment & & Efficiency & \\
Solidarity & & Diligence & \\
& & Compliance & \\
& & Balance & \\
& & Confidentiality & \\
& & Accountability & \\
\hline
\end{tabular}

(see Université du Québec à Chicoutimi) www. (pp.4-15)

A few of them, taking into account their frequency of use and implications in the student environment are: courage, respectfulness, resoluteness, sincerity, humility, reflexivity, morality, responsibility, collaboration, loyalty, integrity (see Macfarlane, B. 2008). 


\section{Methodology}

\subsection{Objective}

Our approach can be considered as an intervention of a constative type which aims to:

$\mathrm{O} 1$ - determine the degree of knowledge and compliance with the rules governing the ethical and academic conduct of students

$\mathrm{O} 2$ - identify risk factors leading to the violation of ethical rules

O3 - provide remedial control mechanisms.

We start from the assumption that many breaches of the Code of Ethics occur as a result of ignorance and/or superficiality in dealing with ethical issues/aspects.

Specific objectives: (as solutions)

1. Involve students in building a culture of integrity in academia.

2. Develop practices and mechanisms for enforcing the academic community's norms of moral and professional conduct at university level.

3. Provide infrastructure to support the development of effective practices.

Participants

The sample consists of 337 undergraduate and master students from all five faculties of the Petroleum and Gas University of Ploiesti: Faculty of Letters and Sciences (49.1\%), Faculty of Economic Sciences (10.1\%), Faculty of Mechanical and Electrical Engineering (18.1\%), Faculty of Oil and Gas Engineering (21.7\%) and Faculty of Petroleum Processing Technology (1\%).

Participating students are mostly (81.6\%) enrolled in the first year $(34.1 \%)$ and second year of studies (47.5\%) respectively.

\subsection{Instruments}

In order to achieve our research objectives, we chose the questionnaire as the research method. The instrument proposed by us contains 10 items grouped around three central issues

- knowledge of the existence of documents governing academic conduct (methodologies, procedures, codes) and their content;

- application of ethical rules;

- the existence of information and awareness-raising actions on academic ethics and their importance.

\section{Results}

In order to achieve the first objective - to determine the degree of knowledge and compliance with the rules governing the ethical and academic conduct of students we considered the following:

- knowledge of the provisions of the Code of University Ethics and Deontology,

- identifying sources of information on this issue,

- identifying the contexts in which students consider it important and necessary to be aware of ethical provisions.

The responses received are grouped as follows:

$60.8 \%$ of the surveyed students state that they have information and are aware of the provisions of the Code of University Ethics and Deontology. We observe a higher degree of knowledge (62\%) among undergraduates compared to 52\% among 
postgraduates. This, given that the subject of Ethics and Academic Integrity is a compulsory subject in master's programmes and only optional in bachelor's programmes. Surprisingly, we also note a higher level of knowledge in the undergraduate examinations in years I (53\%) and II (74\%) compared to years III and IV $(35 \%)$. We say this considering that the latter are preparing for the final exam and are being trained to respect the rules of ethics in the research, production and presentation of their degree papers.

Knowledge of the documents regulating academic ethics is a concern in the academic environment, as demonstrated by the $80.2 \%$ of students who cite professors and debates on the subject in lectures and seminars as their main source of knowledge. In their absence, knowledge of ethical standards would suffer a worrying deficiency, as in less than $10 \%$ of cases the dissemination of information is carried out through faculty/university websites or other means, implying a low interest in selfinformation, self-education. Moreover, we also note that from the answers received it is not possible to establish a correspondence between the need for knowledge and the need for application, or rather, we note a discrepancy between the form and the substance of the problem. Specifically, although $79.8 \%$ of respondents claim the need to be informed about the provisions of the Code of Ethics and University Deontology from the moment of acquiring the status of student, only $18.4 \%$ of them consider this information useful in the context of developing their own materials for course, seminar, laboratory activities. Thus, a number of risk behaviours remain poorly represented in the consciousness of the students participating in our study, such as: plagiarism, incorrect/partial citation, respect of intellectual property, use of the same material in several evaluation situations, distorted and/or misrepresentation of research data, discriminatory and abusive behaviours, aggressive and inappropriate behaviour towards colleagues, professors and the university campus in general (see Figure no. 1. Contexts of awareness of the provisions of the Code of University Ethics and Deontology).

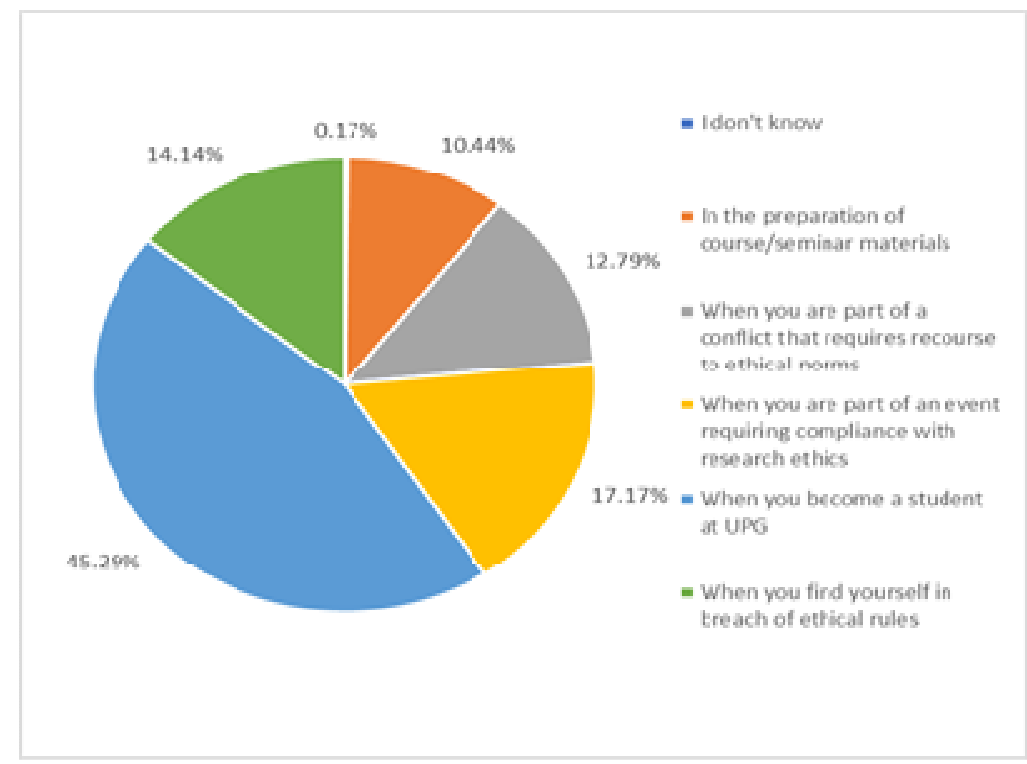

Fig.1. Contexts of awareness of the provisions of the Code of University Ethics and Deontology) 
As regards the application of the rules of academic conduct, the questionnaire aimed to identify the most frequent violations of the rules of conduct, both from the perspective of their degree of knowledge and from that of the actual dealing with the consequences of non-compliance. Analysing the answers, we obtained the following classification (see Fig.2, Frequency of types of violations of professional conduct rules encountered in student work).

- taking information from the Internet without specifying sources $(57.6 \%)$

- presenting someone else's work as their own (49.9\%)

- copying in exams $(48.1 \%)$.

- tolerating fraudulent behaviour by colleagues $(37.1 \%)$

- taking/translating passages from the literature without mentioning the bibliographic source $(36.5 \%)$.

- presenting the same work in several assessment situations $(26.1 \%)$.

- producing fictitious research data $(25.5 \%)$.

(graph question 5)

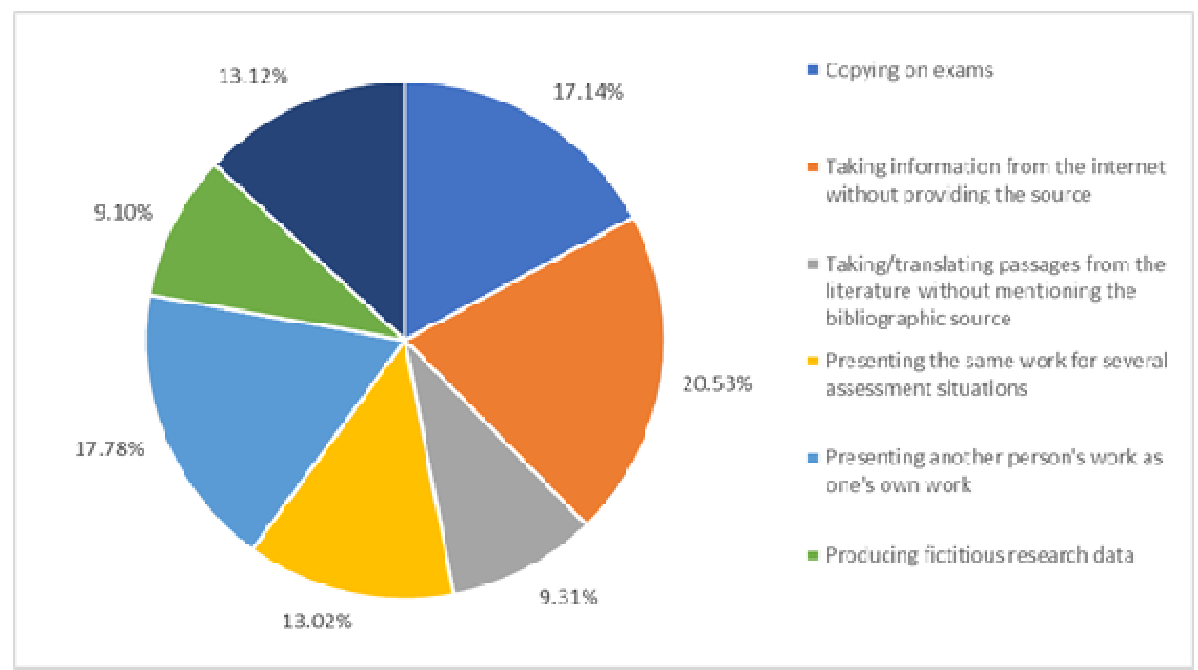

Fig.2. Frequency of types of violations of professional conduct rules encountered in student work)

The above classification reveals a growing practice of deviating from ethical rules in favour of obtaining quick recognition - we are thinking of grades, credits, appreciations - against a false expenditure of effort, time, involvement, interest in authentic knowledge.

However, if we talk about behaviours associated with administered sanctions, $62.9 \%$ claim to have experienced subjectivity in assessment. In other words, there is a discrepancy between their perception of their performance and the assessment grid applied by teachers. If, to these we add "lack of transparency of general interest information for students" and "manifestation of discriminatory attitudes in teaching activity" as the answers with a high frequency in recognizing them as behaviours associated with sanctions, we observe that, when it comes to consequences, they are related by attribution to another person involved and not to their own responsibility. As in the case of moral education, moral awareness is more difficult to form, to educate, it requires time and maturity.

We can put forward the idea that all of these - the lack of desirable behaviour, the mismatch between what is declaratively "politically correct" and what we are actually being told, the percentages regarding conduct in academia, etc. - are also caused by the poor enforceability of the sanctions provided for in the Code of Ethics, a tendency to protect those who are at fault, and the lack of a statistical overview of the frequency and seriousness of undesirable behaviour in academia that could serve as a case study 
of moral value for members of the academic community. In other words, we consider ourselves part of the problem and therefore we consider it appropriate to initiate activities that provide control mechanisms of a remedial nature, especially since so far, according to the responses to the questionnaire, only $58.8 \%$ of students have participated in actions to promote the values that form the basis for building a culture of quality and academic integrity and most of these actions (51.6\%) are part of teaching activities.

\section{Discussions}

"Despite the plethora of research on factors associated with academic dishonesty and ways of averting it, such dishonesty remains a significant concern. There is a need to identify overarching frameworks through which academic dishonesty might be understood, which might also suggest novel yet research-supported practical insights aimed at prevention." (Simola, S., 2017, p. 43).

Our research is part of a series of studies on ethical behavior in academic communities. A similar study was conducted on the Slovak education system and revealed the main issues of academic ethics from the perspective of students. (see Gluchman, V., Gluchmanová, M., 2018, pp. 44-53)

The analysis of the research data allows us to formulate a few ideas, with conclusive value.

Most deviations from ethical norms are the consequence of the lack of knowledge or the superficiality with which ethics is approached in the academic context. This makes it necessary to set up a concrete intervention and accountability approach for all educational actors. In concrete terms, we propose a series of actions, working meetings with students of the faculties of the UPG on the theme of Respect for ethics and academic integrity - risk factors, with the following topics to be addressed:

1.Moral values on the basis of which academic activity is carried out.

2. Moral rules for regulating realities in the academic community.

3. Good practices in the academic space.

4. Serious violations of academic ethics.

5. Research ethics

University Ethics Committee - institutional body with competence in ensuring compliance and rigorous application of the principles of the University Code of Ethics.

Another, equally important, topic leads us to the necessity of raising awareness and internalising ethical conduct in order to avoid the transfer and multiplication of ethical problems from the academic environment to the wider social environment. It is a question of building values-based education and shaping a moral profile that provides future graduates with useful, necessary and sufficient tools for success.

\section{References}

1. Gluchman, V., Gluchmanová, M. (2016). Ethical relationships in the teaching profession in Slovakia. Journal of Educational Sciences \& Psychology, vol. VI (LXVIII) no.2/2016.

2. Gluchman, V., Gluchmanová, M. (2018). Students' views on ethical issues in Slovak education. Journal of Educational Sciences \& Psychology, vol. VIII (LXX), no.1/2018.

3. Löfström, E., Trotman, T., Furnari, M. et al. (2015). Who teaches academic integrity and how do they teach it? High Educ 69, 435-448 (2015). https://doi.org/10.1007/s10734-014-9784-3.

4. Macfarlane, B. (2008). Researching with Integrity. The Ethics of Academic Enquiry. New York: Routledge.

5. Simola, S. (2017). Managing for academic integrity in higher education: Insights from behavioral ethics. Scholarship of Teaching and Learning in Psychology, 3(1), 4357. https://doi.org/10.1037/stl0000076.

6. Université du Québec à Chicoutimi (1996). Guide d'éthique et de déontologie. https://www.uqac.ca/direction_services/secretariat_general/manuel/0/197.pdf 